Cardiology

\title{
Swelling of volar aspect of the wrist
}

R Gudena, N Khetan

Answers on $p$ ell.

A 68 year old patient was admitted to the intensive care unit after a Hartman's procedure for perforated diverticular disease. His postoperative recovery was complicated with respiratory failure, and he was in the intensive care unit for 13 days. During this period he required ventilation, and a right radial artery catheter was inserted for blood pressure monitoring and arterial blood-gas analysis. The arterial catheter was removed after eight days. On the 10th postoperative day a swelling was noticed on the volar aspect of the right wrist (fig 1).

\section{QUESTIONS}

(1) What is the diagnosis?

(2) What are the differential diagnoses?
(3) How do you treat this condition?

Postgrad Med J 2005:81:e9

(http://www.postgradmedj.com/cgi/content/ full $/ 81 / 958 / \mathrm{e} 9$ ).

doi: 10.1136/pgmj.2004.028720

$\ldots \ldots \ldots \ldots \ldots \ldots$

Authors' affiliations

R Gudena, Royal Orthopaedic Hospital,

Birmingham, UK

N Khetan, Wrexam Maleor Hospital,

Wrexham, UK

Correspondence to: Dr R Gudena, Department of Orthopaedics, c/o Mr Thomas, Roya

Orthopaedic Hospital, Birmingham B31 2AP,

UK; gudenar@aol.com

Submitted 14 September 2004

Accepted 23 September 2004

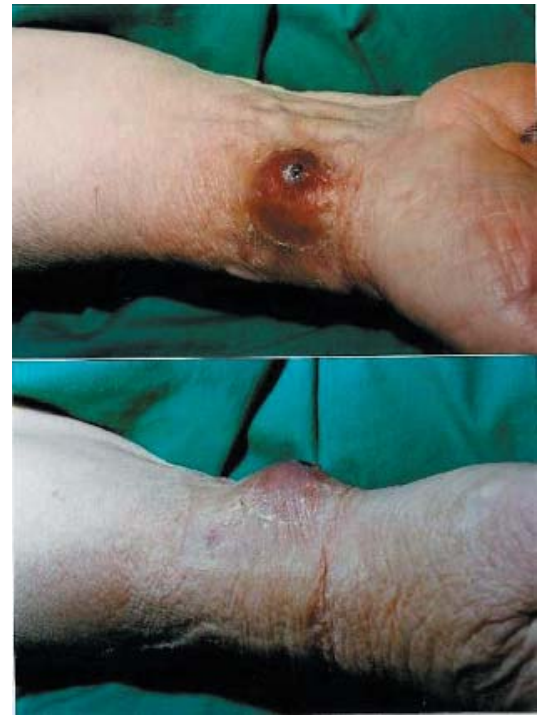

Figure 1 Swelling on the volar aspect of the right wrist. 